\title{
Influence of Proteins on the Perception of Flavored Stirred Yogurts
}

\author{
A. Saint-Eve, C. Lévy, N. Martin, and I. Souchon ${ }^{1}$ \\ Unité Mixte de Recherche de Génie et Microbiologie des Procédés Alimentaires, INA PG-INRA, 78850 Thiverval-Grignon, France
}

\begin{abstract}
Among yogurt dairy components, protein type is known to modify the texture of the products and the volatility of odorous volatile organic compounds. The aim of this study was to investigate the impact of 3 protein ratios (caseinate to total protein) on the sensory properties of $4 \%$ fat, strawberry-flavored stirred yogurts. A sensory methodology study was therefore investigated to choose the most efficient method in terms of sensitivity, quantification, and ease with which the panel could distinguish slight differences in olfactory property between the yogurts. Three kinds of product presentation procedures were compared: a monadic presentation, a comparative presentation, and a comparative presentation with a reference. The results showed that the 3 presentation methods emphasized some important texture differences between the yogurts in the same way. However, the comparative procedure with a reference was the only one to reveal clear olfactory property differences between the yogurts. The main effect of protein ratio variation in yogurt concerned the texture properties, which greatly differed between the 3 yogurts and was confirmed by complex viscosity measurements. Olfactory differences between the yogurts were more subtle. Overall, the flavor intensity and the fruity notes were less intense in the yogurts with the high caseinate ratio than in those with the low ratio. This result was in agreement with the physicochemical measurements, which showed a higher retention of a large majority of aroma compounds of the strawberry flavor in the yogurts with a high caseinate ratio.
\end{abstract}

Key words: texture and olfactory properties, milk protein, yogurt, sensory descriptive analysis

\section{INTRODUCTION}

Flavor is defined as the combination of olfactory, gustatory, and trigeminal sensations perceived during tasting. In our study, the term "odor" refers to the direct olfactory component of flavor (orthonasal perception)

Received August 19, 2005.

Accepted November 6, 2005.

${ }^{1}$ Corresponding author: souchon@grignon.inra.fr and the term "aroma" to the organoleptic properties perceptible by the olfactory organ via the back of the nose; that is, retronasal olfactory perception when tasting (NF ISO 5492, 1995).

Yogurt and fermented milks are among the most common fresh dairy products eaten around the world. Their acceptability by the consumer is largely determined by their sensory properties. The composition and, in particular, the type of milk proteins, can have a great impact on the yogurt texture and on its flavor properties. Therefore, food product flavoring is a complex process because of multiple interactions that can occur between the dairy matrix and the aroma compounds, as well as between texture and flavor properties. Thus, a better understanding of the mechanisms that govern aroma and texture perception could be of great help for the optimization process in yogurt formulation.

As shown in previous studies (Tamime et al., 1984; Kailasapathy and Supriadi, 1998; Sodini et al., 2004), the variations of the type and concentration of milk proteins can modify the perceived texture of yogurts. Tamime et al. (1984) observed that yogurt enriched with caseinates had a visually coarse texture, whereas other yogurts (with skim milk powder) were smooth. However, increasing the level of whey proteins (modification of the whey protein:casein ratio) in the milk base used for yogurt production led to a significant increase in granular texture perception (Kailasapathy and $\mathrm{Su}$ priadi, 1998).

Olfactory properties may also be influenced by protein changes in the matrices but in a different way, depending on the physicochemical properties of the aroma compounds. However, most of the previous studies have been carried out on simple dairy food systems, not on complex systems. For example, the addition of whey protein concentrate to a sucrose solution flavored with vanillin or benzaldehyde was reported to decrease its flavor perception, whereas no impact of caseinate on perceived intensity of benzaldehyde was observed (Hansen and Heinis, 1991, 1992). Reiners et al. (2000) showed that the addition of $\beta$-LG had no effect on the odor perception of vanillin, but significantly decreased the odor intensity of eugenol.

In the present study, we investigated the influence of the protein ratio (caseinate to total protein) on the sensory properties of a complex dairy system-flavored 
stirred yogurts. Therefore, a sensory methodology study was investigated to find the most efficient and sensitive sensory methodology for distinguishing and quantifying slight olfactory property differences between the yogurts. Descriptive analysis is the most widely used technique to assess product sensory properties. It involves the description and quantification of the sensory qualities of a product by trained panelists (Meilgaard et al., 1991; Stone and Sidel, 1993). From a methodological point of view, the choice of the sample presentation mode (monadic or simultaneous) is a critical experimental factor, especially when quantifying the sensory property differences between relatively similar products.

The memory required to perform the sensory evaluation will differ, depending on the sample presentation mode (Thirion et al., 1995). In the comparative (or simultaneous) mode, the judgment is quite independent of the long-term memory. It is formed when the subject tastes the products and can be modified as soon as the subject receives new information (Hastie and Park, 1986). In the monadic presentation, the judgment is based, to a greater extent, on the memory of the references learned beforehand. In this case, the judgment is built on the recovery of information stored both in the short-term and in the long-term memory, requiring much more memory than in the comparative mode.

Some researchers find the simultaneous presentation procedure more attractive (McBride, 1982). It is faster to implement than the monadic method because less time is required to train the panelists. The studies undertaken to compare the monadic and comparative modes of presentation (Larson-Powers and Pangborn, 1978; McBride, 1986; Thirion et al., 1995; Mazzuchelli and Guinard, 1999) all showed a better discrimination ability of the panelists in the comparative procedure than in the monadic procedure. When different samples are presented side by side, the assessors are able to detect very small differences (McBride, 1982) and make precise judgments about the relative differences. The monadic procedure may be more appropriate in some cases when the experimenter wants to minimize the influence of small visual differences between the products on the other sensory properties (Stone and Sidel, 1993). The monadic presentation is generally considered sufficiently sensitive, less tiring, and faster than the comparative procedure (Mazzucchelli and Guinard, 1999), and is more appropriate when a large number of products are studied.

The main objective of the present study was to investigate the impact of protein ratio on sensory properties. The products were flavored stirred yogurts that varied slightly in their protein composition. Therefore, the efficiency of 3 sample presentation procedures-monadic,
Table 1. Premix composition for yogurt preparation

\begin{tabular}{lccc}
\hline & \multicolumn{3}{c}{ Yogurt type $^{1}$} \\
\cline { 2 - 4 } Ingredients $^{2}$ & CAS & MPO & WP \\
\hline Water, L (Volvic, Danone) & 1 & 1 & 1 \\
Skim milk powder, g (Ingredia) & 100 & 135 & 100 \\
Lactose, g (Ingredia) & 21 & - & 21 \\
Sodium caseinate, g (Ingredia) & 14 & - & - \\
Whey protein, g (Ingredia) & - & - & 14 \\
Anhydrous milk fat, g (Lactalis) & 40 & 40 & 40 \\
Sugar, g (sucrose) (Daddy) & 50 & 50 & 50 \\
Protein total content, \% & 5.4 & 5.4 & 5.4 \\
Dry matter, \% & 22.50 & 22.50 & 22.50 \\
\hline
\end{tabular}

${ }^{1}$ Yogurts: CAS $=$ yogurt with caseinate to total protein ratio of $86 \%$ (corresponding to the protein mixture fortified with sodium caseinates); MPO = yogurt with caseinate to total protein ratio of $81 \%$ (corresponding to the protein mixture fortified with milk powder); and WP = yogurt with caseinate to total protein ratio of 60\% (corresponding to the protein mixture fortified with whey protein).

${ }^{2}$ Suppliers: Danone, Volvic, France; Ingredia, Arras, France; Lactalis, Isigny, France; and Daddy, Paris, France.

comparative, and comparative with a reference-was compared to determine the most sensitive descriptive procedure to investigate and quantify subtle olfactory differences. The results of the sensory analysis were compared with physicochemical characterizations (rheological measurements and aroma compound release) to support our observations and conclusions.

\section{MATERIALS AND METHODS}

\section{Products}

Three flavored stirred yogurts were studied. They had the same DM (22.5\%), fat (4\%), and protein (5.4\%) content. The composition of the yogurts is presented in Table 1. Only the protein ratio (caseinate to total protein) varied: a ratio of $86 \%$ (corresponding to the protein mixture fortified with sodium caseinates: CAS), a ratio of $81 \%$ (corresponding to the protein mixture fortified with milk powder: MPO), and a ratio of $60 \%$ (corresponding to the protein mixture fortified with whey protein: WP). The MPO yogurt was considered the reference product.

Yogurt premix reconstitution and yogurt fermentation were performed in the laboratory. Each milk base was heated at $92^{\circ} \mathrm{C}$ for $5 \mathrm{~min}$. The fermentation was carried out in a 7-L fermenter (SGI, Toulouse, France), maintained at a constant temperature of $44^{\circ} \mathrm{C}$. The milks were inoculated with Lactobacillus delbrueckii ssp. bulgaricus (LB18 incorporated in $0.005 \%$ in milk), and Streptococcus thermophilus (ST7 and ST143 in $0.01 \%$ ) provided by Chr. Hansen (Arpajon, France). Fermentation was stopped when the $\mathrm{pH}$ reached 4.6, and the yogurts were immediately stored at $4^{\circ} \mathrm{C}$. 
Table 2. Aroma compound composition of strawberry aroma mixed with propylene glycol and their concentrations in yogurt

\begin{tabular}{lc}
\hline Aroma compound & $\begin{array}{l}\text { Concentration } \\
\text { in yogurt } \\
(\mathrm{mg} / \mathrm{kg})\end{array}$ \\
\hline Butanoic acid & 2.21 \\
Decanoic acid & 1.11 \\
Hexanoic acid & 1.12 \\
Diacetyle & 4.34 \\
Ethyl acetate & 17.88 \\
Ethyl butyrate & 27.24 \\
Ethyl hexanoate & 22.44 \\
Ethyl octanoate & 1.14 \\
Methyl cinnamate & 2.2 \\
Furaneol & 18.47 \\
$\gamma$-decalactone & 2.52 \\
Hexanal & 1.01 \\
Z-3-hexenol & 23.68 \\
Limonene & 2.23 \\
Linalol & 1.88 \\
Maltol & 32.53 \\
Vanillin & 15.72 \\
\hline
\end{tabular}

The yogurts were flavored with $0.1 \%(\mathrm{wt} / \mathrm{wt}$ ) strawberry flavoring containing 17 odorous compounds mixed with propylene glycol (Aldrich, Steinheim, Germany). The concentrations of the aroma compounds ranged from 1.01 to $32.53 \mathrm{mg} / \mathrm{kg}$ of yogurt (Table 2).

\section{Physicochemical Measurements}

To control and characterize the 3 products, rheological properties (complex viscosity measured at the 0.1and 100-Pa constraint with a frequency of $1 \mathrm{~Hz}$ ) were determined (details given in Paçi Kora et al., 2004).

The solid-phase microextraction (SPME) method was used to quantify the aroma compounds of the strawberry aroma released in the vapor phase above the different yogurts. The analysis of the aroma compound release was carried out at $4^{\circ} \mathrm{C}$ by SPME using a gas chromatograph flame-ionization detector. A 2-h extraction with a polydimethylsiloxane fiber (PDMS, $100 \mu \mathrm{m}$ film thickness) was performed. The oven program lasted $37.5 \mathrm{~min}$ and started at $50^{\circ} \mathrm{C}$, increasing $4^{\circ} \mathrm{C} /$ min up to $70^{\circ} \mathrm{C}$; increasing $5^{\circ} \mathrm{C} / \mathrm{min}$ up to $170^{\circ} \mathrm{C}$; increasing $8^{\circ} \mathrm{C} / \mathrm{min}$ up to $220^{\circ} \mathrm{C}$, and $6 \mathrm{~min}$ at $220^{\circ} \mathrm{C}$. Results obtained from SPME were expressed as area units. Each headspace analysis was done in triplicate.

\section{Sensory Evaluation}

Panelists. The panel consisted of 10 members of the laboratory staff (from 22 to 41 yr old, 4 women and 6 men), recruited according to their motivation and availability to pursue a 4-mo study with 2 sessions per week. Six panelists had previous experience in sensory evaluation of dairy products but all 10 panelists were trained in preliminary sessions for this specific study, as described below.

Training and Set-Up of the Sensory Study. Nine training sessions were carried out. They involved 1) the identification of the basic tastes in water and yogurts, and the ranking of several yogurts according to their sweetness and sourness; 2 ) the evaluation of the texture properties of several yogurts; 3) the identification and the recognition of the odor and aroma quality of each of the 17 aroma compounds entering into the composition of the strawberry flavor as well as the complete flavoring in water or yogurts; and 4) the proper use of the unstructured linear scale to evaluate the intensity of the odor and aroma of flavored yogurts.

The generation of the attributes used for the sensory profile was carried out during a specific session where the 3 different flavored stirred yogurts of the study were presented. A list of 58 attributes was composed. In a subsequent session, the panelists agreed on a reduced list of 34 attributes (Table 3).

Sensory Procedure. Products were presented in 3digit coded, white plastic isothermal pots $(40 \mathrm{~g} / \mathrm{pot})$ stored at $4^{\circ} \mathrm{C}$. The samples were at approximately $10^{\circ} \mathrm{C}$ when they were tested. Panelists were provided with mineral water and plain crackers for palate cleansing between samples. The sessions were carried out in an air-conditioned room at $20^{\circ} \mathrm{C}$ under white lighting in individual booths. Data acquisition was assisted by FIZZ software (Biosystèmes, 1999). For the descriptive analysis, the samples were arranged for each subject according to a Latin square. For a single subject, the order of presentation of the products was the same, regardless of the replication and the profiling procedure.

The 3 types of descriptive procedures were applied and each was replicated over 6 sessions. The different profiles and their replications did not run in the same order for each subject. The reference product (MPO) was systematically replicated within a session, which means that 4 products were tested at each session.

The Monadic Profile. The products were presented one after the other for each subject. For each sample, the panelists scored the perceived intensity of each attribute on an unstructured scale anchored with the terms "very weak" and "very intense." The attributes were evaluated in the following order: visual texture with a spoon, odor, aroma, taste, and texture-in-mouth.

The Comparative Profile. The products were simultaneously presented to each subject. The panelists scored the intensity of each attribute of the different yogurts on a single scale identical to the one used in the monadic profile. The panelists evaluated the attributes of visual texture with a spoon, odor, and texturein-mouth with the first series of pots. A second series 
Table 3. List of the 34 attributes used for the descriptive analyses ${ }^{1}$

\begin{tabular}{|c|c|c|c|c|}
\hline Odor attributes & Aroma attributes & $\begin{array}{l}\text { Taste } \\
\text { attributes }\end{array}$ & $\begin{array}{l}\text { Visual texture } \\
\text { attributes }\end{array}$ & $\begin{array}{l}\text { Texture-in-mouth } \\
\text { attributes }\end{array}$ \\
\hline $\begin{array}{l}\text { O-Overall intensity } \\
\text { O-Lacteous } \\
\text { O-Fruity } \\
\text { O-Solvent } \\
\text { O-Green } \\
\text { O-Butter } \\
\text { O-Caramel } \\
\text { O-Vanillin } \\
\text { O-Animal }\end{array}$ & $\begin{array}{l}\text { A-Overall intensity } \\
\text { A-Lacteous } \\
\text { A-Fruity } \\
\text { A-Strawberry } \\
\text { A-Kiwi } \\
\text { A-Pineapple } \\
\text { A-Apple } \\
\text { A-Peach } \\
\text { A-Solvent } \\
\text { A-Green } \\
\text { A-Caramel } \\
\text { A-Vanillin } \\
\text { A-Butter } \\
\text { A-Animal }\end{array}$ & $\begin{array}{l}\text { T-Sweet } \\
\text { T-Sour }\end{array}$ & $\begin{array}{l}\text { V-Shiny } \\
\text { V-Granular } \\
\text { V-Thick } \\
\text { V-Ropy }\end{array}$ & $\begin{array}{l}\text { M-Granular } \\
\text { M-Thick } \\
\text { M-Unctuous } \\
\text { M-Mouth-coating } \\
\text { M-Astringent }\end{array}$ \\
\hline
\end{tabular}

${ }^{1} \mathrm{O}=$ Odor (orthonasal perception); $\mathrm{A}=$ aroma (retro-nasal perception); $\mathrm{T}$ = taste; $\mathrm{V}=$ visual texture (with a spoon); $\mathrm{M}=$ texture in mouth.

was then delivered to the panelists to evaluate the intensities of aroma and taste attributes to limit product heating.

The Comparative Profile with a Reference. The 4 products were simultaneously presented to the panelists. Among these, one product (MPO yogurt) was identified as the reference and identified with the letter "R." The other 3 products were coded with 3 random digits. For each sensory attribute, the panelists scored the intensity of all 3 samples by comparing each to the reference, whose intensity was located in the middle of the unstructured scale varying from "much less intense than R" to "much more intense than R." The order of the attributes for the evaluation was the same as in the standard comparative profile. As in the comparative profile, 2 sets of pots were delivered to the panelists.

\section{Data Analyses}

All data analyses were performed using the SAS software package, version 9.1 (SAS Institute, 2005). Two approaches were used to discriminate the products and compare the efficiency of the 3 profiling methods: a univariate and a multivariate analysis.

For each of the 3 procedures, a 3-way ANOVA was carried out separately on each attribute according to the following model: attribute $=$ product + repetition + subject + product $\times$ repetition + subject $\times$ product. When significant product differences were observed $(P<0.05)$, product mean intensities were compared using the Newman-Keuls multiple comparison test.

The Newman-Keuls test is univariate and does not take into account the possible links between the sensory attributes. Consequently, a multivariate approach was also applied, the PROC STEPDISC procedure of SAS, to perform stepwise discrimination analysis. This pro- gram was used to select the olfactory attributes that contribute the most to the discriminatory power of the model with $P=0.15$. A linear discriminant analysis (PROC DISCRIM procedure of SAS) was also carried out to explore the performance of discriminant functions using preliminary attributes selected after stepwise discrimination analysis (SAS Institute, 2005).

Panel performances were monitored. The intersession repeatability of the panel and its homogeneity were evaluated based on the repetition and product $\times$ repetition effects of the 3-way ANOVA described above. Intrasession replicates were averaged for this analysis. The intrasession repeatability of the panel was then measured by a Student's $t$-test between the 2 replicated samples of the MPO product in each profile. The Student's $t$-test was considered significant for a probability lower than 5\%. Finally, the consensus between the panelists was evaluated by loading at the product $\times$ subject interaction, resulting from the ANOVA presented in intersession repeatability.

\section{RESULTS}

First, the results of the 3 sensory procedures were compared to select the most sensitive sensory method to highlight texture and olfactory differences between the yogurts, considering panel performances. Then, the results of the main objective (the influence of the protein ratio on the texture and olfactory properties) were presented, supported by the physicochemical measurements.

\section{Selection of the Most Sensitive Sensory Profile}

Texture Differences. The 3 profiles produced similar results in relation to texture attributes. According 
Table 4. Significant product effect of the ANOVA for the 3 types of sensory profiles with Fisher $(F)$ values and associated probabilities

\begin{tabular}{|c|c|c|c|c|c|c|}
\hline \multirow[b]{2}{*}{ Attribute $^{1}$} & \multicolumn{2}{|c|}{ Monadic profile } & \multicolumn{2}{|c|}{$\begin{array}{l}\text { Classical comparative } \\
\text { profile }\end{array}$} & \multicolumn{2}{|c|}{$\begin{array}{l}\text { Comparative profile } \\
\text { with a reference }\end{array}$} \\
\hline & $\begin{array}{l}F \text {-value } \\
{[2,32]}\end{array}$ & $P$-value & $\begin{array}{l}F \text {-value } \\
{[2,32]}\end{array}$ & $P$-value & $\begin{array}{l}F \text {-value } \\
{[2,32]}\end{array}$ & $P$-value \\
\hline V-Shiny & 9.08 & 0.001 & 1.11 & NS & 4.84 & 0.0159 \\
\hline V-Granular & 68.22 & $<0.0001$ & 38.91 & $<0.0001$ & 44.45 & $<0.0001$ \\
\hline V-Thick & 36.35 & $<0.0001$ & 19.01 & $<0.0001$ & 14.92 & $<0.0001$ \\
\hline V-Ropy & 20.67 & $<0.0001$ & 28.68 & $<0.0001$ & 14.65 & $<0.0001$ \\
\hline M-Granular & 95.41 & $<0.0001$ & 98.25 & $<0.0001$ & 20.38 & $<0.0001$ \\
\hline M-Thick & 52.5 & $<0.0001$ & 8.7 & 0.0012 & 12.09 & 0.0002 \\
\hline M-Unctuous & 14.73 & $<0.0001$ & 11.37 & 0.0006 & 8.44 & 0.0014 \\
\hline M-Mouth-coating & 12.21 & 0.0004 & 6.44 & 0.0052 & 4.83 & 0.0161 \\
\hline M-Astringent & 4.87 & 0.0157 & 11.49 & 0.0002 & 5.2 & 0.0165 \\
\hline O-Overall intensity & 5.5 & 0.0099 & 0.78 & NS & 4.87 & 0.0139 \\
\hline O-Green & 5.83 & 0.0079 & 0.01 & NS & 4.87 & 0.0156 \\
\hline A-Fruity & 0.53 & NS & 1.15 & NS & 4.07 & 0.0285 \\
\hline A-Kiwi & 0.22 & NS & 1.73 & NS & 4.6 & 0.0191 \\
\hline A-Pineapple & 2.4 & $\mathrm{NS}$ & 0.2 & NS & 4.74 & 0.0172 \\
\hline
\end{tabular}

\footnotetext{
${ }^{1} \mathrm{~V}=$ Visual texture (with a spoon); $\mathrm{M}=$ texture in mouth; $\mathrm{O}=$ odor (orthonasal perception); $\mathrm{A}=$ aroma (retro-nasal perception).
}

NS $=$ Nonsignificant $(P>0.05)$.

to ANOVA (Table 4), the 3 yogurts were significantly discriminated on all 9 texture attributes, both in the monadic profile and in the comparative procedure with a reference profile, and for 8 of them in the standard comparative profile. The 3 profiling methods led to different $F$-values for the same attributes. The mean $F$ product value of the significant texture attributes was higher for the monadic profile (42.6) than for the comparative profile (28.2) and for the comparative procedure with a reference product (17.2; Figure 1a).

Olfactory Differences. The ANOVA on olfactory attributes showed different results as a function of the type of presentation modes (Table 4). The standard comparative profile seemed to be the least relevant for discriminating between the products according to their olfactory properties. No odor or aroma attribute showed significant differences between the products. In the monadic profile, the products only significantly differed on 2 olfactory attributes: green odor and overall odor intensity. In the comparative procedure with a reference, the products showed significant differences on 5 olfactory attributes: overall intensity of the odor, green odor, fruity aroma, kiwi aroma, and pineapple aroma. Moreover, the mean $F$-value of the odor and aroma attributes obtained using the simultaneous presentation procedure with a reference was slightly higher (1.69) than the mean $F$-value obtained with the monadic procedure (1.19) and the standard simultaneous procedure (0.64; Figure 1b).

These results were confirmed by multivariate analyses (Table 5). As for the olfactory attributes, only one of them (overall odor intensity) could discriminate the
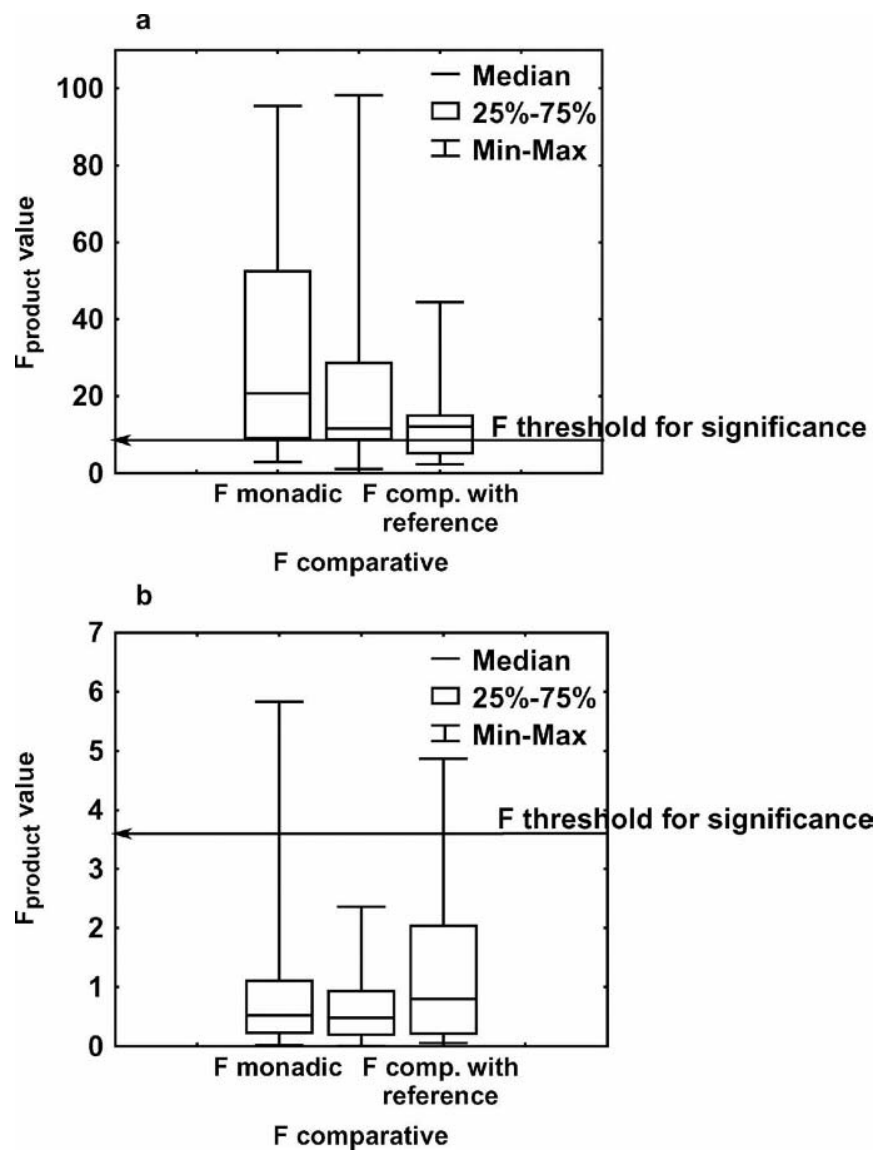

Figure 1. Box plots of the $F$-values for texture (a) and olfactory (b) attributes for the different profiles (monadic, comparative, and comparative with reference); $F$-limit is the threshold for significance. 
Table 5. List of the attributes selected by stepwise analyses for the 3 profile types from the olfactory attributes to discriminate the 3 yogurts

\begin{tabular}{|c|c|c|c|c|c|c|}
\hline \multicolumn{3}{|c|}{ Monadic profile } & \multirow{2}{*}{$\begin{array}{c}\begin{array}{c}\text { Comparative } \\
\text { profile }\end{array} \\
\text { Attribute }\end{array}$} & \multicolumn{3}{|c|}{ Comparative profile with a reference } \\
\hline Attribute $^{1}$ & $F$ & $P$ & & Attribute & $F$ & $P$ \\
\hline O-Overall intensity & 2.45 & 0.096 & - & $\begin{array}{l}\text { A-Pineapple } \\
\text { O-Green } \\
\text { A-Fruity } \\
\text { A-Overall intensity } \\
\text { A-Peach } \\
\text { A-Vanillin }\end{array}$ & $\begin{array}{l}4.42 \\
4.2 \\
2.01 \\
2.71 \\
2.39 \\
2\end{array}$ & $\begin{array}{l}0.016 \\
0.020 \\
0.143 \\
0.075 \\
0.102 \\
0.146\end{array}$ \\
\hline
\end{tabular}

${ }^{1} \mathrm{O}=$ Odor (orthonasal perception); $\mathrm{A}$ = aroma (retro-nasal perception).

3 products $(P<0.1)$ in the monadic profile and none in the standard comparative profile. In the comparative profile with a reference, 6 of the aroma and odor attributes could together discriminate the 3 products $(P<$ 0.15): pineapple aroma, green odor, fruity aroma, overall intensity of the aroma, peach aroma, and vanillin aroma (listed in order of importance).

Overall, and regardless of the type of sensory profile, the yogurts showed clear differences regarding texture, but more subtle differences regarding olfactory properties, which means that the protein ratio variation in the yogurts more strongly influenced the texture properties than the olfactory properties of the yogurts.

However, the 3 methods similarly highlighted the considerable texture differences between the yogurts, and presented different aptitudes for distinguishing weak aroma and odor differences between the yogurts. The comparative profile with a reference appeared to be the most sensitive for discriminating the 3 flavored yogurts based on their olfactory properties alone.

Panel Performances. The results of the intersession repeatability of the panel are presented in Table 6 . The monadic profile and the comparative profile with a reference were the most repeatable profiles, and the standard comparative procedure the least. Concerning intrasession repeatability, the monadic profile was the least repeatable, and the comparative procedure the most. The comparative profile with a reference was intermediate. The $\mathrm{F}_{\text {productxsubject value was used to evalu- }}$ ate the panel consensus. Panelists were globally homogeneous in their notation (Figure 2).

\section{Influence of Protein Ratio on Yogurt Sensory Properties}

Because the comparative profile with a reference appeared to be the most sensitive procedure for distinguishing the subtle olfactory differences between the yogurts, this method was used to investigate the influence of the protein ratio on the texture and olfactory properties.

Influence of Proteins on Texture Properties and Complex Viscosity of Yogurts. The yogurts differing in their caseinate ratio presented clear differences in their texture properties. The yogurt with the highest caseinate ratio (CAS yogurt) was visually judged to be

Table 6. Sensory attributes ${ }^{1}$ for which there is not a good agreement between the panelists over the intrasession and intersession repetitions

\begin{tabular}{|c|c|c|c|}
\hline & Monadic profile & Comparative profile & $\begin{array}{l}\text { Comparative profile } \\
\text { with a reference }\end{array}$ \\
\hline $\begin{array}{l}\text { No. of significant } \\
\text { attributes (out of } 34 \text { ) } \\
\text { Intersession repetition }^{2}\end{array}$ & $\begin{array}{l}4 \\
\text { V-Granular; O-Fruity; M-Mouth- } \\
\text { coating; and O-Lacteous }\end{array}$ & $\begin{array}{l}10 \\
\text { M-Unctuous; O-Overall intensity; } \\
\text { O-Fruity; O-Butter; A-Lacteous; } \\
\text { A-Strawberry; A-Kiwi; A-Peach; } \\
\text { A-Solvent; and A-Butter }\end{array}$ & $\begin{array}{l}6 \\
\text { V-Granular; V-Thick; } \\
\text { V-Ropy; O-Overall } \\
\text { intensity; A-Animal; } \\
\text { and M-Thick }\end{array}$ \\
\hline
\end{tabular}

${ }^{1} \mathrm{O}=$ Odor (orthonasal perception); $\mathrm{A}=$ aroma (retro-nasal perception); $\mathrm{T}$ = taste; $\mathrm{V}=$ visual texture (with a spoon); $\mathrm{M}=$ texture in mouth .

${ }^{2}$ Attributes for which the repetition factor and product $\times$ repetition interaction are significant (ANOVA, $P<0.05$ ).

${ }^{3}$ Attributes for which there is a significant difference between the 2 intrareplicates of MPO (Student's test, $P<0.05$ ). 


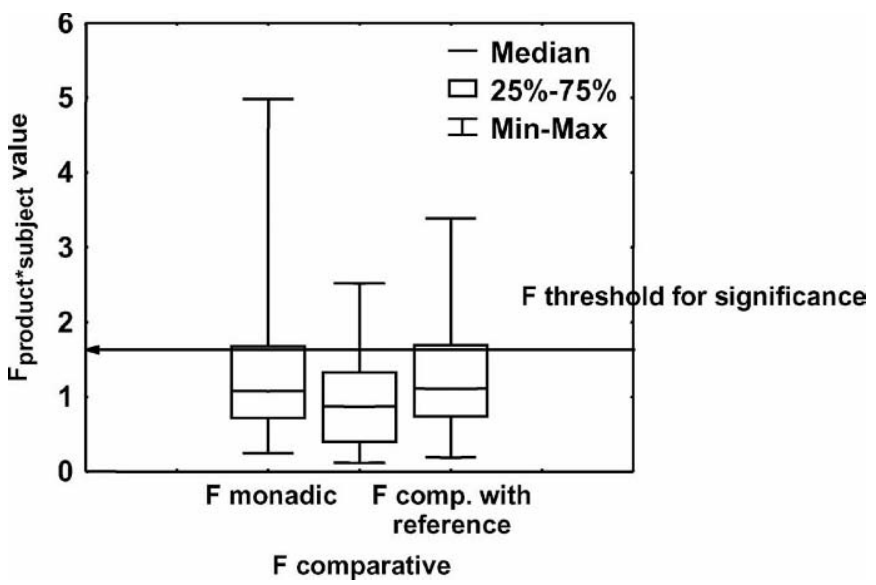

Figure 2. Consensus between panelists by representation of $F$ product $\times$ subject value to box plot for the 3 profile types (monadic, comparative, and comparative with reference).

more granular, thicker, and less shiny than the MPO yogurt. In the mouth, the CAS yogurt also appeared to be more granular, more astringent, less mouth-coating, and less unctuous than MPO yogurt (Figure 3). The yogurt with the lowest caseinate ratio (WP yogurt) was visually perceived as being less thick and ropier, and less granular, less thick, and less astringent in the mouth than the MPO yogurt. The MPO yogurt appeared to be as shiny and granular as the WP yogurt, and somewhere intermediate in the case of the CAS and WP yogurts in relation to the thick and ropy properties. In the mouth, the MPO yogurt with the intermediate caseinate ratio was similar to the WP yogurt for the unctuous and mouth-coating properties, and similar to the CAS yogurt for the thickness.

Concerning the rheological measurements, the protein ratio had a strong effect on the complex viscosity of yogurt. At low shear stress, the CAS yogurt had the highest complex viscosity $(79.2 \pm 9.7 \mathrm{~Pa} \cdot \mathrm{s}$, mean $\pm \mathrm{SD})$. The WP yogurt was the least viscous $(38.1 \pm 4.4 \mathrm{~Pa} \cdot \mathrm{s})$, and the MPO yogurt was intermediate $(52.7 \pm 17.4 \mathrm{~Pa} \cdot \mathrm{s}$; Figure 4).

Influence of Proteins on Olfactory Properties and Flavor Release of Yogurts. The results of the univariate analysis (Figure 5) showed how the olfactory properties of the strawberry flavoring of the yogurts are modified by the protein ratio in the dairy matrix. Concerning the olfactory properties (Figure 5), the overall odor intensity, green odor, and fruity aroma were perceived as being more intense in WP yogurt than in MPO yogurt. On the contrary, the CAS yogurt was perceived as being less intense in fruity and kiwi aromas than the MPO yogurt. The MPO reference product was perceived as being more intense in pineapple aroma than WP yogurt or CAS yogurt.
The multivariate analysis was performed on olfactory data for the comparative profile with a reference. Pineapple aroma, green odor, fruity aroma, overall intensity aroma, peach aroma, and vanillin aroma together allowed good discrimination of the 3 flavored yogurts (see Table 4). Three of these 6 attributes were the same as the ones selected with the univariate approach. The 3 attributes that were not selected in the univariate analysis were overall intensity aroma, peach aroma, and vanillin aroma, which varied in the same way as the more global fruity aroma. The discriminant analysis carried out on these 6 attributes is illustrated in Figure 6 and gives a clearer picture of the olfactory characteristics that made it possible to distinguish the products in this olfactory perceptual space.

Concerning the aroma release measured by SPME, the release of only 7 aroma compounds discriminated the 3 yogurts by 1 -way ANOVA $(P<0.05)$, from among the 17 compounds of the strawberry aroma that were quantified: ethyl hexanoate, hexanal, ethyl octanoate, methyl cinnamate, ethyl acetate, Z-3-hexenol, and ethyl butyrate (Figure 7). As in the sensory analysis, the results were compared with the reference product (MPO yogurt). The CAS yogurt was characterized by lower release of aroma compounds, except for Z-3hexenol compared with the MPO yogurt. The WP yogurt presented the highest release, especially for ethyl octanoate. The release of ethyl butyrate and methyl cinnamate was higher in MPO yogurt than in CAS and WP yogurts. However, variations of aroma release were quite low between yogurts: about 10 to $30 \%$ of variation between CAS and MPO yogurts and less than $10 \%$ between WP and MPO yogurts.

\section{DISCUSSION}

Yogurts differing in their protein ratio presented different texture characteristics; the increase of the caseinate ratio led to a thicker and more granular texture. This observation is in agreement with the rheological measurements carried out on studied yogurts and the observations reported by several authors in the literature-lower viscosity was observed for a yogurt enriched with WP than for a yogurt enriched with MPO (Cho et al., 1999; Guzmán-González et al., 1999, 2000). The fact that the yogurt with the highest caseinate ratio was the most granular corroborates the results of Tamime et al. (1984), who reported that yogurt enriched with sodium caseinate exhibits a coarse texture when visually assessed, whereas yogurt enriched with milk powder is smoother. According to those authors, the difference is due to large casein particles and robust micellar chains observed in the microstructure of the yogurts fortified with sodium caseinate. This hypothe- 


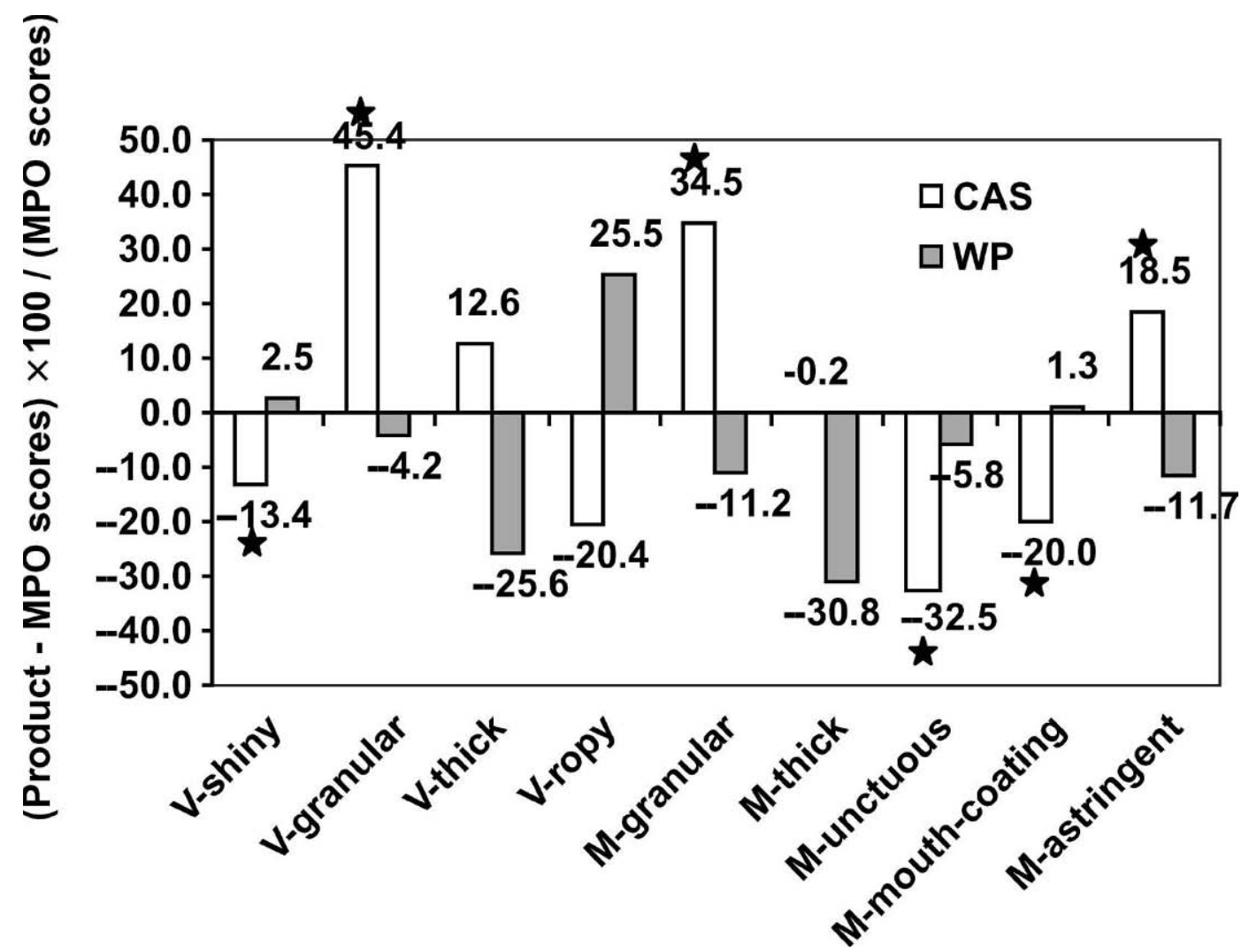

Figure 3. Percentage of deviation between MPO yogurt and CAS yogurt or WP yogurt sensory intensities on the significant texture attributes by 3-way ANOVA. *Significant differences between MPO and CAS or WP by Student's $t$-test $(P<0.05)$. CAS $=$ Yogurt with caseinate to total protein ratio of $86 \%$ (corresponding to the protein mixture fortified with sodium caseinates); MPO = yogurt with caseinate to total protein ratio of $81 \%$ (corresponding to the protein mixture fortified with milk powder); and WP = yogurt with caseinate to total protein ratio of $60 \%$ (corresponding to the protein mixture fortified with whey protein). $\mathrm{O}=$ Odor (orthonasal perception); $\mathrm{A}=$ aroma (retronasal perception); $\mathrm{T}=$ taste; $\mathrm{V}=$ visual texture (with a spoon); $\mathrm{M}=$ texture in mouth.

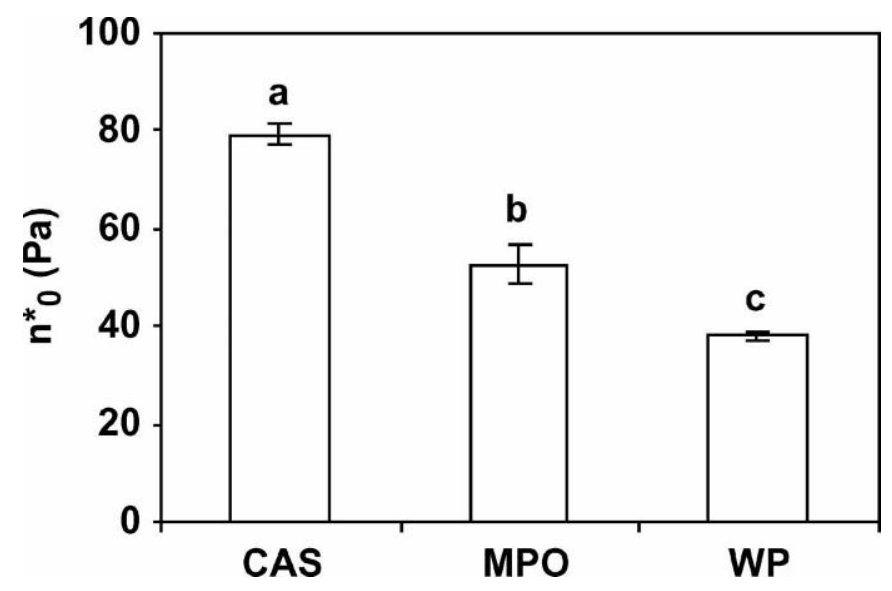

Figure 4. Complex viscosity and confidence intervals at low shear stress of $0.1 \mathrm{~Pa}\left(\eta^{*} 0\right)$ shear stress of yogurts at $10^{\circ} \mathrm{C} .{ }^{\mathrm{a}-c} \mathrm{Means}$ with different letter superscripts differ significantly at $P<0.05$. sis about the heterogeneity of the microstructure could explain the granular properties of the CAS yogurt.

In our study, the type of protein also influenced the flavor properties of the yogurts. Yogurts enriched with caseinates were perceived as being less intense for a majority of olfactory notes, contrary to the yogurt with the lowest caseinate ratio. The SPME analysis showed higher retention of the aroma compounds by the CAS yogurts than by the WP or the MPO yogurts. Physicochemical bindings between the aroma compounds and the matrices could also explain the olfactory differences between the yogurts. The hypothesis of Hansen and Booker (1996) is in agreement with our results and could explain the higher olfactory intensity of WP yogurt. These authors observed that a protective effect occurs for citral in acid citric solutions when casein is present. They assumed that the sodium caseinate formed a more open micellar structure in solution with hydrophilic and hydrophobic patches, so there were fewer strong interactions within nonpolar binding sites on $\beta$-LG (Hansen and Booker, 1996). However, these 


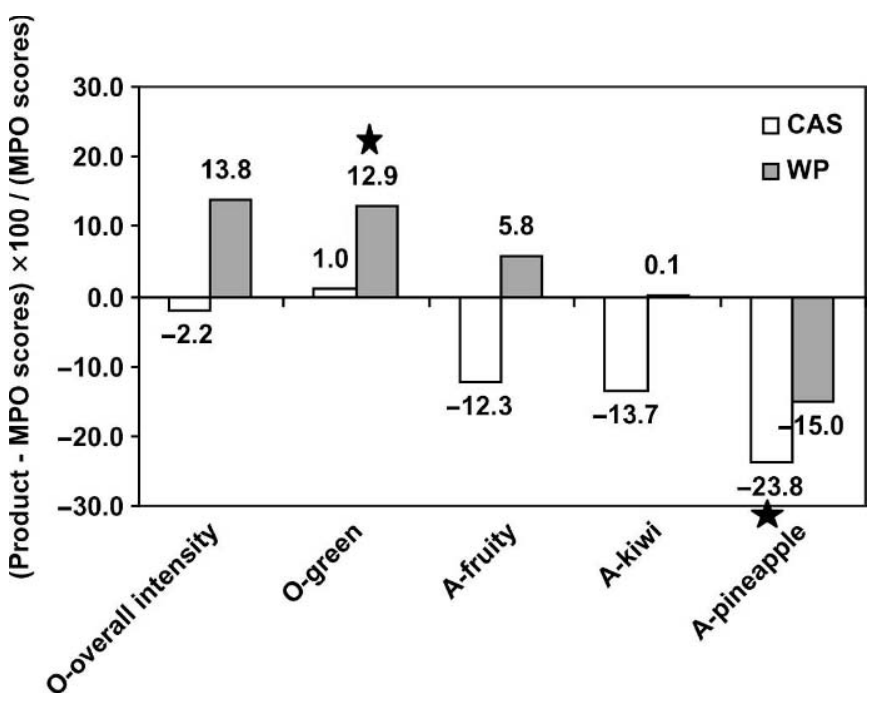

Figure 5. Percentage of deviation between MPO yogurt and CAS yogurt or WP yogurt sensory intensities on the significant olfactory attributes by 3-way ANOVA. *Significant differences between MPO yogurt and CAS or WP yogurts by Student's $t$-test $(<5 \%)$. CAS = Yogurt with caseinate to total protein ratio of $86 \%$ (corresponding to the protein mixture fortified with sodium caseinates); MPO = yogurt with caseinate to total protein ratio of $81 \%$ (corresponding to the protein mixture fortified with milk powder); and WP = yogurt with caseinate to total protein ratio of $60 \%$ (corresponding to the protein mixture fortified with whey protein). $\mathrm{O}=$ Odor (orthonasal perception); $\mathrm{A}$ = aroma (retro-nasal perception).

results were not in agreement with those of Hansen and Heinis (1991, 1992), who found that the addition of whey protein to sucrose solutions (2.5\%) flavored with vanillin, citral, benzaldehyde, and D-limonene decreased the intensity of retronasal olfactory properties more than casein. The authors proposed different hypotheses to explain why solutions with higher caseinate content were perceived as being more intense than the others. Structure and amino acid composition of the dairy proteins (caseinates and $\beta$-LG) can explain the differences in flavor properties. Different types of physicochemical interactions between milk proteins and aroma compounds could be the reason. Vanillin, benzaldehyde, and D-limonene may interact with the retinolbinding site or with other sites near the surface of the protein $(\beta-\mathrm{LG})$, resulting in decreased concentration of flavor compounds available for sensory properties by the panelist.

In the present study, the physicochemical interactions between aroma compounds and proteins can explain the olfactory property differences observed between the yogurts in this study. Because the differences in flavor release were relatively low (a maximum of 30\% variation of the aroma quantity between the yogurts), it would also be possible that the physicochemical differences were not adequate to explain all the changes in the olfactory properties of the yogurts. Therefore, the role of sensory interactions must be taken into account. Indeed, interactions between texture and flavor perceptions could explain the differences between yogurts rather than the physicochemical bindings (Weel et al., 2002; Paçi Kora et al., 2004). As reported by Paçi Kora et al. (2004), sensory analysis results (low intensity in the green note of thickened yogurts) could not be explained by specific interactions between the thickening agent and hexanal (no effect on release under equilibrium and dynamic conditions). Thus, in the present study, the sensory properties of yogurt flavor could also be influenced by a change in texture perception; the CAS yogurt was perceived as being thicker than

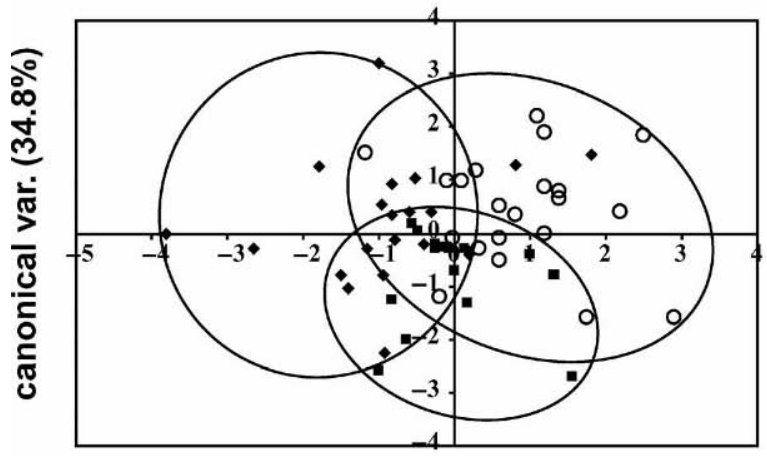

canonical var. $(65.2 \%)$ b

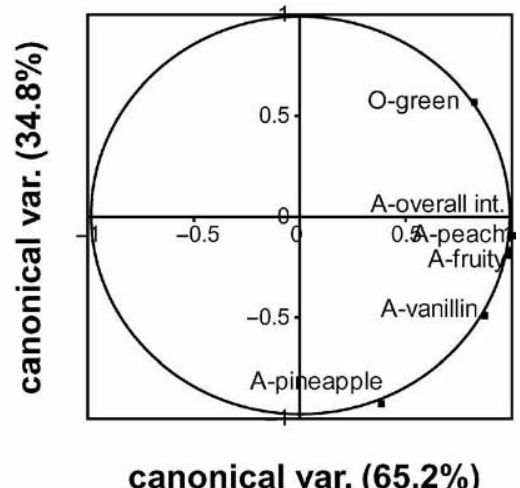

Figure 6. Product mapping (a) of the factorial discriminant analysis with CAS yogurt $(\diamond)$, MPO yogurt (匹), and WP yogurt (o). Variables (6 olfactory attributes) map, obtained with the comparative profile with a reference (b). CAS = Yogurt with caseinate to total protein ratio of $86 \%$ (corresponding to the protein mixture fortified with sodium caseinates); MPO = yogurt with caseinate to total protein ratio of $81 \%$ (corresponding to the protein mixture fortified with milk powder); and WP = yogurt with caseinate to total protein ratio of $60 \%$ (corresponding to the protein mixture fortified with whey protein). $\mathrm{O}=$ Odor (orthonasal perception); $\mathrm{A}=$ aroma (retro-nasal perception). 


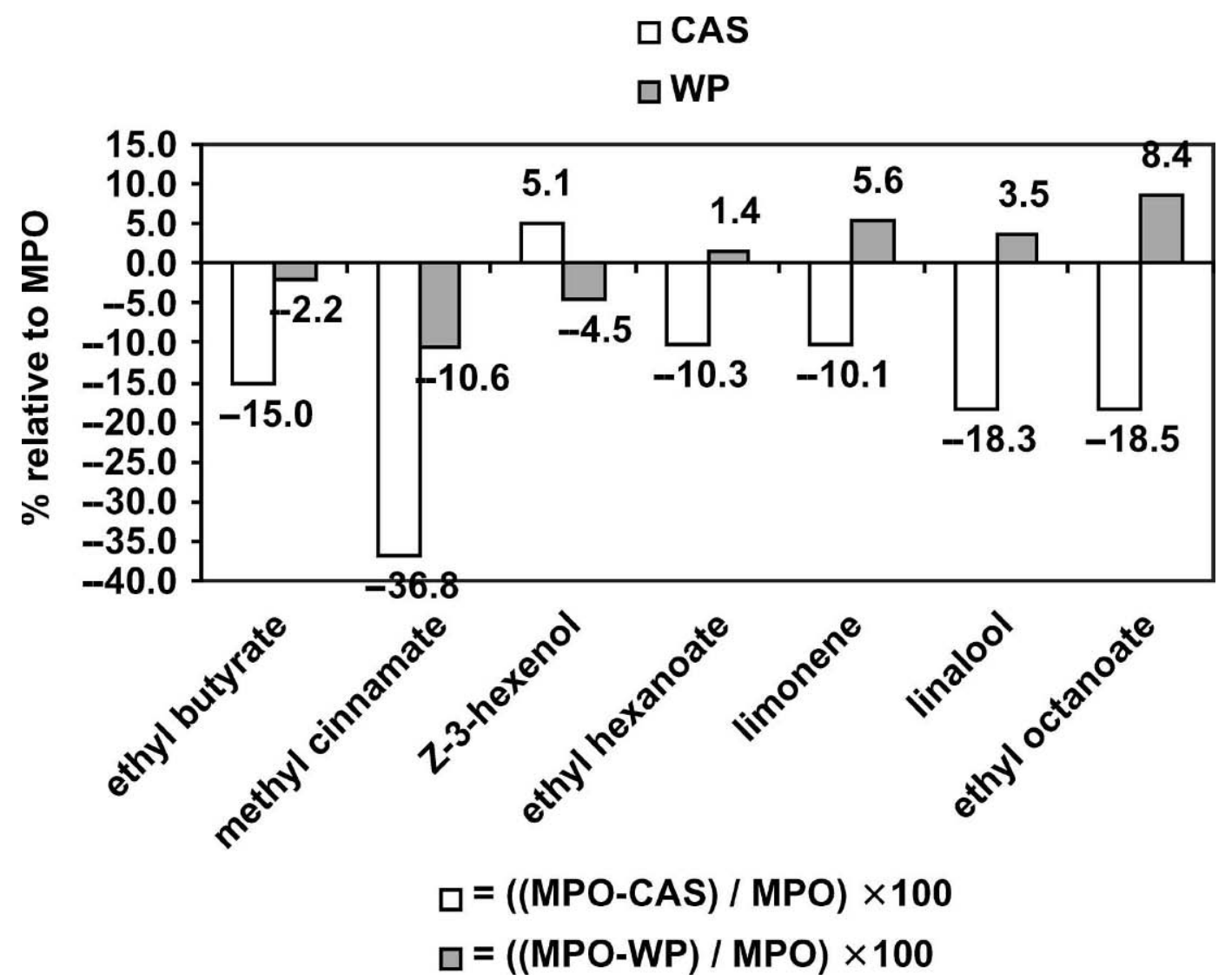

Figure 7. Percentage of deviation of the significant aroma compounds by the solid-phase microextraction method (1-way ANOVA) between MPO yogurt and CAS or WP yogurts. CAS = Yogurt with caseinate to total protein ratio of 86\% (corresponding to the protein mixture fortified with sodium caseinates); MPO = yogurt with caseinate to total protein ratio of $81 \%$ (corresponding to the protein mixture fortified with milk powder); and WP = yogurt with caseinate to total protein ratio of $60 \%$ (corresponding to the protein mixture fortified with whey protein).

the other yogurts and had a less intense odor and aroma. This could be the result of texture-aroma interactions linked to cognitive associations, as well as the result of different chewing behaviors adopted by the subjects when the texture of products is different.

The quantitative descriptive analysis of food products can be considered one of the most complex sensory tasks (Stone and Sidel, 1993). Indeed, panelists have to analyze their perceptions when tasting the product, verbalize them, and quantify them relative to the product sensory space under study (Lesschaeve and Issanchou, 1996). Yogurts were better discriminated by texture attributes than by olfactory attributes. This observation confirms the results of Lundgren et al. (1986), Pangborn et al. (1978), Wendin et al. (1997), and Paçi Kora et al. (2003). Texture differences between the products were probably more obvious and thus easier to evaluate. The limited capacity of the panelists to differentiate between products based on olfactory attributes can first be explained by the difficulty of the task
(Paçi Kora et al., 2003). Indeed, the panelists were asked to evaluate each olfactory note separately, even if the aroma compound proportion and its concentration in the yogurts did not vary.

Concerning the type of procedure, the comparative procedure with a reference appeared to be the most sensitive for detecting slight olfactory differences between the products, and that is why it was selected. It could be assumed that panelists would be less tired with the comparative procedure with a reference than with a standard comparative profile, because the number of comparisons between the products is lower. Compared with the monadic profile, the comparative profile is supposed to be an easier task, given that panelists can immediately appreciate the extent of the diversity of the product space to evaluate the intensity of each product. Moreover, in the monadic profile, the memory load required for the subjects is greater than in comparative profiles, because it includes the memory of the references and that of the products proposed during the 
training at the same time. Moreover, the tasted product can be influenced by the evaluation of the previously tasted product. But, in our study, the panelists found that the 2 types of comparative profiles required more effort and were more difficult to perform than the monadic profile. We can explain this phenomenon by the double task required in standard comparative profiles: evaluating the absolute intensity of each product and comparing it with the other products.

Moreover, in the comparative procedure, the panelists are more likely to get bored and tired if there are a large number of products and attributes to evaluate. In the present study, the order of presentation of the yogurts, but not the attributes, was arranged according to a Latin square; consequently, for the attributes evaluated last in a sensory session, the panelists might be more tired and less sensitive. This is exactly what we observed regarding the intersession repeatability of the attributes that were evaluated last (aromas) in our study. Moreover, the intrasession repeatability of the monadic profile was not as good as the one of the comparative profile. This might be because the evaluation of 2 identical products presented in the same time (MPO replicate) is easier than when they are evaluated one after the other. This result confirmed those of Mazzuchelli and Guinard (1998), who observed that the repeatability of the panel was better with the simultaneous presentation mode than with the monadic presentation mode.

In any case, the present study shows that the influence of the protein ratio on the olfactory properties is not easy to assess with complex products such as yogurts. Considering the methodological aspects of the sensory procedure, the comparative procedure with a reference appeared to be the most sensitive for the panelists to discriminate relatively similar products. This efficient and robust method could be useful for further sensory studies and particularly when there is a reference product.

\section{CONCLUSIONS}

This work demonstrates that the modifications of the protein ratio (caseinate to total protein) influenced the sensory properties of flavored stirred yogurts. To distinguish the olfactory property differences between the studied yogurts, the choice of a comparative procedure with a reference appeared to be the most efficient. Thus, the comparative profile with a reference appears to be a potentially useful procedure for discriminating relatively similar products.

Concerning the influence of proteins on sensory properties, the yogurts showed large differences in texture, whereas olfactory differences were smaller. There was strong agreement between the rheological properties (complex viscosity) and texture attributes (thickness) of the yogurts. Moreover, the olfactory characteristics were in agreement with the release by the different yogurts of a majority of aroma compounds; the yogurt with a high caseinate ratio retained the majority of aroma compounds and was perceived as being less intense than the 2 other yogurts. The opposite was observed for yogurt with a low caseinate ratio.

This study contributes to a better understanding of the impact of formulation on sensory properties. The variation of protein composition in dairy product formulation can generate a broad range of textures. However, the modification of flavor properties must be taken into account during flavoring. Further experiments are in progress to study the kinetics of release by matrices and to understand the mechanisms that govern sensory properties in flavored dairy complex matrices.

\section{ACKNOWLEDGMENTS}

This work was supported by the French government (CANAL-ARLE project). The authors gratefully acknowledge the scientific contribution of the participants. The authors are indebted to G. Wagman for revising the English version of the manuscript.

\section{REFERENCES}

Biosystèmes. 1999. Fizz: Logiciel de gestion de l'analyse sensorielle et des tests consommateurs. Couternon, France.

Cho, Y. H., J. A. Lucey, and H. Singh. 1999. Rheological properties of acid milk gels as affected by the nature of the fat globule surface material and heat treatment of milk. Int. Dairy J. 9:537-545.

Guzmán-González, M., F. Morais, and L. Amigo. 2000. Influence of skimmed milk concentrate replacement by dry dairy products in a low-fat set-type yoghurt model system. Use of caseinates, coprecipitate and blended dairy powders. J. Sci. Food Agric. 80:433-438.

Guzmán-González, M., F. Morais, M. Ramos, and L. Amigo. 1999. Influence of skimmed milk concentrate replacement by dry dairy products in a low fat set-type yoghurt model system. I: Use of whey protein concentrates, milk protein concentrates and skimmed milk powder. J. Sci. Food Agric. 79:1117-1122.

Hansen, A. P., and D. C. Booker. 1996. Flavor food interactions, ACS symposium series 633. Pages 75-89 in Flavor interactions with casein and whey protein. American Chemical Society, Washington, DC.

Hansen, H., and J. J. Heinis. 1991. Decrease of vanillin flavor perception in the presence of casein and whey proteins. J. Dairy Sci. 74:2936-2940.

Hansen, H., and J. J. Heinis. 1992. Benzaldehyde, citral and D-limonene flavor perception in the presence of casein and whey proteins. J. Dairy Sci. 75:1211-1215.

Hastie, R., and B. Park. 1986. The relationship between memory and judgment depends on whether the judgment task is memory based or on line. Psychol. Rev. 93:258-268.

Kailasapathy, K., and D. Supriadi. 1998. Effect of partially replacing skim milk powder with whey protein concentrate on the sensory qualities of lactose hydrolysed acidophilus yoghurt. Milchwissenschaft 53:385-389.

Larson-Powers, N., and R. M. Pangborn. 1978. Paired comparison and time-intensity measurements of the sensory properties of 
beverages and gelatins containing sucrose or synthetic sweeteners. J. Food Sci. 43:41-46.

Lesschaeve, I., and S. Issanchou. 1996. Could selection tests detect the future performance of descriptive panellists? Food Qual. Pref. 7:177-183.

Lundgren, B., B. Lundgren, R. M. Pangborn, N. Daget, M. Yoshida, D. G. Laing, R. L. McBride, N. Griffiths, L. Hyvönen, F. Sauvageot, K. Paulu, and N. Barylko-Pikielna. 1986. An interlaboratory study of firmness, aroma, and taste of pectin gels. Lebensm. Wiss. Technol. 19:87-88.

Mazzuchelli, R., and J. X. Guinard. 1999. Comparison of monadic and simultaneous sample presentation modes in a descriptive analysis of milk chocolate. J. Sens. Stud. 14:235-248.

McBride, R. L. 1982. Range bias in sensory evaluation. J. Food Technol. 17:405-410.

McBride, R. L. 1986. Hedonic rating of food: Single or side by side sample presentation? J. Sens. Stud. 21:355-363.

Meilgaard, M. C., G. V. Civille, and B. T. Carr. 1991. Sensory evaluation techniques. Pages 188-199 in Descriptive analysis techniques. CRC Press, London, UK.

NF ISO 5492 (Norme Francais-International Organization for Standardization 5492). 1995. Contrôle de la qualité des produits alimentaires-Analyse sensorielle. Pages 27-51 in Receuil de normes française. AFNOR (Agence française de normalisation), Paris, France.

Paçi Kora, E., E. Latrille, I. Souchon, and N. Martin. 2003. Textureflavor interactions in low fat stirred yogurt: How mechanical treatment, thickener concentration and aroma concentration affect perceived texture and flavor. J. Sens. Stud. 18:367-390.

Paçi Kora, E., I. Souchon, E. Latrille, N. Martin, and M. Marin. 2004. Composition rather than viscosity modifies the aroma compound retention of flavored stirred yogurt. J. Agric. Food Chem. 52:3048-3056.

Pangborn, R. M., Z. M. Gibbs, and C. Tassan. 1978. Effect of hydrocolloids on apparent viscosity and sensory properties of selected beverages. J. Texture Stud. 9:415-436.

Reiners, J., S. Nicklaus, and E. Guichard. 2000. Interaction between $\beta$-lactoglobulin and flavour compounds of different chemical classes. Impact of the protein on the odour perception of vanillin and eugenol. Lait 80:347-360.

SAS Institute. 1990. User's Guide: Statistics. Version 9.1 ed. SAS Inst., Inc., Cary, NC.

Sodini, I., F. Remeuf, S. Haddad, and G. Corrieu. 2004. The relative effect of milk base, starter, and process on yogurt texture: A review. Crit. Rev. Food Sci. Nutr. 44:113-137.

Stone, H., and J. Sidel. 1993. Sensory evaluation practices. Pages 202-242 in Descriptive Analysis. 2nd ed. Academic Press, Inc., London, UK.

Tamime, A. Y., M. Kalab, and G. Davies. 1984. Microstructure of setstyle yoghurt manufactured from cow's milk fortified by various methods. Food Microstruct. 3:83-92.

Thirion, S., J. F. Martin, S. Rousset-Akri and C. Touraille. 1995. Comparaison de deux modes de présentation d'échantillons en analyse sensorielle. Pages 127-134 in 4émes journées agro-industrielles et méthodes statistiques, Dijon, France.

Weel, K., A. Boelrijk, A. Alting, P. Van Mil, J. Burger, H. Gruppen, A. Voragen, and G. Smit. 2002. Flavor release and perception of flavored whey protein gels: Perception is determined by texture rather than by release. J. Agric. Food Chem. 50:5149-5155.

Wendin, K., R. Solheim, T. Allmere, and L. Johanson. 1997. Flavour and texture in sourmilk affected by thickeners and fat content. Food Qual. Pref. 8:281-291. 